\title{
La geolocalización del trabajador. Reflexiones a la luz de la jurisprudencia reciente
}

\section{The geolocation of the worker. Reflections in the light of recent jurisprudence}

\author{
Mirentxu Marín Malo \\ Profesora Asociada Doctora de Derecho del Trabajo y de la Seguridad Social \\ Universidad Pública de Navarra
}

ORCID ID: 0000-0002-9081-6155

Recibido: 31/10/19

Aceptado: 11/12/19

doi: https://doi.org/10.20318/labos.2020.5302

\begin{abstract}
Resumen: $\quad$ En los últimos años, gracias a las nuevas tecnologías, el poder de control del empresario ha aumentado mediante el uso de estas con el objetivo de verificar la prestación de servicio por parte del trabajador. El control de la jornada, la video vigilancia en el tiempo de trabajo o los programas que permiten acceder al ordenador del trabajador son algunos ejemplos de esta vigilancia exhaustiva de la prestación del servicio. Sin embargo, estas medidas no están exentas de polémica. La jurisprudencia se ha visto obligada a determinar los límites a su uso con el objetivo de proteger los derechos de los trabajadores. El presente trabajo pretende analizar los límites que la jurisprudencia ha puesto a la geolocalización del trabajador durante la jornada laboral.
\end{abstract}

Palabras clave: nuevas tecnologías, geolocalización, poder de control, intimidad, trabajo.

Abstract: $\quad$ Over the last years, thanks to new technologies, the control power of the employer has increased through the use of these technologies with the purpose of controlling the provision of service by the worker. Control of the working day, the video surveillance during working time or programs that allow access to the worker's computer are some examples of this exhaustive monitoring of the provision of the service. However, these measures are not without controversy. Case law has been forced to determine the limits to its use in order to protect workers' rights. This paper aims to analyze the limits that jurisprudence has established to the geolocation of the worker during the working day.

Keywords: new technologies, geolocation, control power, privacy, work.

\section{Introducción}

La facultad de control del empresario, reconocida en el art. 20 del RDLeg. 2/2015, de 23 de octubre, por el que se aprueba el texto refundido de la Ley del Estatuto de los Trabajadores (en adelante, TRET), es ampliamente conocida y ha sido abordada, en numerosas ocasiones tanto por la doctrina como por la jurisprudencia. En concreto, establece éste artículo que "el empresario podrá adoptar las 
medidas que estime más oportunas de vigilancia y control para verificar el cumplimiento por el trabajador de sus obligaciones y deberes laborales", siempre, claro está, respetando la dignidad del trabajador y otros derechos que puedan verse afectados por las medidas adoptadas, como puede ser el derecho a la intimidad del mismo ${ }^{1}$.

Las nuevas tecnologías, por su parte, permiten nuevas formas de control empresarial de la prestación del servicio del trabajador casi ilimitadas, que facilitan al empresario un conocimiento detallado del comportamiento de sus trabajadores durante la jornada laboral ${ }^{2}$. Obviamente, este aumento potencial del poder de vigilancia puede poner en peligro el equilibrio entre el poder de control empresarial y los derechos de los trabajadores. Como señalan algunos autores, "se introduce un elemento nuevo en el sinalagma contractual capaz de provocar la ruptura en el necesario equilibrio de intereses" entre empresario y trabajador ${ }^{3}$.

Quizás por todo ello, la Ley Orgánica 3/2018, de 5 de diciembre, de Protección de Datos Personales y Garantía de los Derechos Digitales (en adelante, LOPDyDD) incluyó, en su Disposición Final Decimotercera un art. 20 bis al TRET, donde se establece que "los trabajadores tienen derecho a la intimidad en el uso de los dispositivos digitales puestos a su disposición por el empleador, a la desconexión digital y a la intimidad frente al uso de dispositivos de video vigilancia y geolocalización en los términos establecidos en la legislación vigente en materia de protección de datos personales y garantía de los derechos digitales".

En todo caso, el uso de dispositivos de geolocalización para controlar la prestación de servicios por parte de los empleados está cada vez más extendido. En la actualidad, muchos trabajadores prestan sus servicios a distancia, a través de plataformas digitales o debiendo desplazarse de un lugar a otro para la realización del trabajo. Esto es habitual en comerciales y empresas de transporte y reparto de mercancías, supuestos que, por la conflictividad de la medida de geolocalización adoptada, han llegado a los tribunales españoles en varias ocasiones.

La cuestión sobre la posibilidad y límites establecidos a la geolocalización del trabajador por parte de la empresa ha suscitado no pocos problemas, debido a la posibilidad de que dicha medida invada la esfera íntima de la persona, protegida por el derecho fundamental del art. $18 \mathrm{CE}$, que implica "el derecho a la libertad frente a las potenciales agresiones a la dignidad y a la libertad de la persona provenientes de un uso ilegítimo del tratamiento automatizado de datos"s. Así, se ha señalado que la limitación de los derechos fundamentales del trabajador como consecuencia del poder empresarial de control y dirección solo puede derivarse de que la propia prestación y naturaleza del servicio implique esta restricción. Además, en todo caso, la medida adoptada deberá respetar el principio de proporcionalidad, atendiendo a la idoneidad de la medida para la consecución del objetivo propuesto; la necesidad de la misma, en tanto que no exista otra medida destinada al mismo fin y la proporcionalidad estricta, en tanto que la medida adoptada deberá ser equilibrada en relación al fin perseguido ${ }^{6}$.

\footnotetext{
${ }^{1}$ Abordando este tema en profundidad, MARTÍNEZ FONS, D.: El poder de control del empresario en la relación laboral, CES, Madrid, 2002. En este sentido, véase STC núm. 29/2013, de 11 de febrero (rec. 10522/2009), donde se seńala que los avances tecnológicos constantes permiten que el empresario, en el ejercicio de su poder de control, incida en mayor medida en la vida privada de los trabajadores, lo que supondría una injerencia en la misma y por tanto una vulneración de su derecho a la intimidad.

${ }^{2}$ En este sentido, TASCÓN LÓPEZ, R.: "El lento (pero firme) proceso de decantación de los límites del poder de control empresarial en la era tecnológica”, en Revista Doctrinal Aranzadi Social, núm. 17, 2007, p. 2.

${ }^{3}$ FERNÁNDEZ DOMÍNGUEZ, J.J. y RODRÍGUEZ ESCANCIANO, S.: Utilización y control de datos laborales automatizados, Agencia de Protección de Datos, Madrid, 1997, p. 87.

${ }^{4}$ En este sentido, véase GONII SEIN, J.L.: "Nuevas tecnologías digitales, poderes empresariales y derechos de los trabajadores. Análisis desde la perspectiva del Reglamento Europeo de Protección de Datos de 2016”, en Revista de Derecho Social, núm. 78, 2017.

${ }^{5}$ STC núm. 254/1993, de 20 de julio (rec.1827/1990).

${ }^{6}$ En este sentido, véase SEMPERE NAVARRO, A.V. y SAN MARTIN MAZZUCCONI, C.: Nuevas tecnologias y relaciones laborales, Aranzadi, Cizur Menor, 2002, p. 46, donde señalan que se exige también que la medida de control esté justificada; entendiendo por ello que su adopción responda a motivaciones objetivas distintas de la simple voluntad arbitraria y caprichosa del empresario de controlar cuestiones no laborales.
} 
La Agencia Española de Protección de Datos (en adelante, AEPD) ha señalado, en su Informe núm. 193/2008 que los datos obtenidos a través del sistema de geolocalización (rutas seguidas, tiempos de parada, velocidad, etc.) están asociados a información concerniente a una persona física identificable, en tanto que solo pueden corresponder al conductor del vehículo en un momento determinado, por lo que estos datos deben ser considerados datos de carácter personal, amparados por la normativa en esta materia.

Este artículo tiene por objeto analizar brevemente la jurisprudencia en materia de geolocalización del trabajador, atendiendo a la posible vulneración por parte del empresario de los derechos del trabajador a su intimidad y a la protección de datos de carácter personal al instalar medios de geolocalización en los equipos de trabajo, así como determinar el estado actual de la cuestión planteando, en su caso, las posibles controversias que es previsible enfrentar en un futuro no muy lejano.

\section{Los dispositivos de geolocalización en los eqipos de trabajo facilitados por la empresa}

En la actualidad, son varios los pronunciamientos jurisprudenciales en relación con la posibilidad de la empresa de implantar sistemas de geolocalización como medida de control de la prestación del servicio por parte de sus trabajadores. Antes de abordar el contenido de estas, debe señalarse que, en su mayoría, abordan la posible vulneración del derecho fundamental del trabajador a la intimidad (art. $18 \mathrm{CE}$ ) derivada de la implantación de dicho dispositivo, teniendo en cuenta que los datos obtenidos a través del mismo llevan, en ocasiones, al despido del trabajador por el incumplimiento de sus obligaciones contractuales ${ }^{7}$.

En relación con el derecho a la intimidad del trabajador, la jurisprudencia viene señalando que, ante la instalación de dispositivos de geolocalización en los vehículos utilizados por los mismos, tanto dentro como fuera de su jornada laboral, y con el objetivo de proteger el ámbito de la vida privada de la persona y su derecho constitucional, el trabajador deberá ser informado sobre la instalación del sistema de geolocalización en el vehículo puesto a su disposición por parte de la empresa. En todo caso, estos dispositivos solo deberán estar en funcionamiento durante la jornada laboral del trabajador pues, como establece el art. 87 LOPDyDD, "el empleador podrá acceder a los contenidos derivados del uso de medios digitales facilitados a los trabajadores a los solos efectos de controlar el cumplimiento de las obligaciones laborales o estatutarias y de garantizar la integridad de dichos dispositivos". De lo anterior se deduce que, una vez haya finalizado la jornada laboral y fuera del tiempo de trabajo, será preciso que el empresario cuente con el consentimiento previo del trabajador para mantener activados los sistemas de geolocalización, sin que pueda ampararse en su poder de dirección y control que, conforme al art. 20.3 TRET le permite "adoptar las medidas que estime más oportunas de vigilancia y control para verificar el cumplimiento por el trabajador de sus obligaciones $y$ deberes laborales's, siempre, claro está, respetando el derecho a la dignidad del trabajador, pero, reconociendo en el art. 20 bis TRET el derecho del trabajador "a la intimidad en el uso de los dispositivos digitales puestos a su disposición por el empleador, a la desconexión digital y a la intimidad frente al uso de dispositivos de videovigilancia y geolocalización".

\footnotetext{
${ }^{7}$ Es el caso de la STSJ Asturias, núm. 2191/2017, de 3 de octubre (rec. 1908/2017), donde se reconoce la procedencia del despido basado en la prueba obtenida mediante el dispositivo de geolocalización instalado en la Tablet, propiedad de la empresa, que el trabajador debía mantener encendida a lo largo de su jornada laboral, habiendo sido informado de la instalación de dicho sistema de geolocalización.

${ }^{8}$ En relación al consentimiento del trabajador en el tratamiento de datos en la relación laboral, véase LLORENS ESPADA, J.: "La negociación colectiva como fuente reguladora en el tratamiento de datos y los nuevos derechos digitales", en El futuro del trabajo. 100 años de la OIT. XXIX Congreso Anual de la Asociación Española de Derecho del Trabajo y de la Seguridad Social, Ministerio de Trabajo, Migraciones y Seguridad Social, 2019, pp. 1435 y ss.
} 
Además, el acceso por el empleador a los contenidos derivados del uso de este tipo de medios digitales de control de la prestación del servicio estará siempre sujeto al principio de proporcionalidad, respetando los derechos fundamentales de los trabajadores, especialmente (por ser el directamente afectado) su derecho a la intimidad recogido en el art. $18 \mathrm{CE}^{9}$. Con el objetivo de proteger este derecho a la intimidad, el art. 87.3 LOPDyDD establece que "los empleadores deberán establecer criterios de utilización de los dispositivos digitales", contando para ello con la participación de los representantes de los trabajadores. Asimismo, continúa estableciendo que "el acceso por el empleador al contenido de dispositivos digitales respecto de los que haya admitido su uso con fines privados requerirá que se especifiquen de modo preciso los usos autorizados y se establezcan garantías para preservar la intimidad de los trabajadores", como, por ejemplo, cuándo podrán ser utilizados para esos fines privados y con qué límites ${ }^{10}$.

Tal como ha señalado la STSJ Madrid núm. 260/2014, de 21 de marzo de 2014 (rec. 1952/2013), los datos de los trabajadores así obtenidos y su tratamiento están protegidos por el art. $18 \mathrm{CE}$, en tanto que "permiten conocer en todo momento durante su uso parcelas de la vida del trabajador que por muy imbricadas que estén en el desarrollo de la relación laboral con la empresa inciden potencialmente en la esfera de su derecho a la intimidad personal y, de ser objeto de tratamiento al que le asiste la protección de datos de tal carácter". Por ello, si bien es cierto que para tomar acciones encaminadas a controlar la prestación de servicios durante la jornada laboral no es necesario el consentimiento del trabajador, éste sí deberá ser informado de los medios de control adoptados y de la finalidad para la que han sido implantados, así como de quién será el responsable del fichero de almacenamiento de datos, el tratamiento que ser dará a los mismos y cómo debe el interesado ejercitar sus derechos de acceso, rectificación, cancelación y oposición respecto a dichos datos.

No se plantea duda alguna, para la jurisprudencia, esta cuestión. Ejemplo de ello se encuentra en la sentencia mencionada. El supuesto de hecho, en este caso, es el siguiente. Un trabajador es despedido tras haber instalado la empresa en el vehículo cedido al mismo, para su uso exclusivamente profesional, un sistema de geolocalización y comprobar que el trabajador no hacía del vehículo el uso para el que se había previsto, ante lo que interpone demanda al considerar que se ha vulnerado su derecho a la intimidad y que la prueba obtenida resulta ilícita, en tanto que no había sido informado de que el sistema de geolocalización permitía un continuo y permanente seguimiento del vehículo durante su uso, "no solo del posicionamiento de este por razones de seguridad, sino también del lugar exacto en donde se hallaba el trabajador y, a su vez, con el posterior tratamiento de los datos obtenidos con una finalidad totalmente distinta a la anunciada, y por tanto, sin conocimiento del conductor". Según la Sala, todo esto supone que las conclusiones extraídas del dispositivo de geolocalización que la empresa presenta como prueba para amparar el despido del trabajador y su justificación en un incumplimiento contractual "constituyan un procedimiento que vulnera los derechos fundamentales"; cuestión que ya había sido advertida por la propia Agencia Española de Protección de Datos (en adelante, AEPD) en su Informe 193/2008, donde se hacía alusión al caso de la implantación del sistema de geolocalización en una empresa informando al trabajador únicamente de la potestad empresarial de tomar esta medida al amparo del art. 20 TRET, sin especificar los derechos del trabajador en relación al tratamiento de los datos obtenidos mediante dicho sistema, lo que vulnera la intimidad del mismo y supone la ilicitud de la medida adoptada.

\footnotetext{
${ }^{9}$ En este sentido, véase GONZÁLEZ GONZÁLEZ, C.: "Control empresarial de la actividad laboral mediante la videovigilancia y colisión con los derechos fundamentales del trabajador. Novedades de la Ley Orgánica 3/2018, de 5 de diciembre, de Protección de Datos Personales y garantía de los derechos digitales”, en Aranzadi Digital, núm. 1/2018.

${ }^{10}$ A este respecto, se ha señalado por parte de la jurisprudencia la necesaria "información previa y expresa, precisa, clara e inequivoca a los trabajadores de la finalidad de control de la actividad laboral a la que la captación podía ser dirigida". Analizando esta y otras cuestiones, GONZÁLEZ GONZÁLEZ, C.: "Control empresarial de la actividad laboral, videovigilancia y deber informativo. A propósito de la STC de 3 de marzo de 2016”, en Revista Aranzadi Doctrinal, núm. 5, 2016, donde se analiza en profundidad esta sentencia y sus consecuencias.
} 
Similar supuesto se plantea en la STSJ Madrid, núm. 739/2014 de 29 de septiembre (rec. 1993/2013), fallando la Sala, de nuevo a favor de la trabajadora y considerando el despido como improcedente por la ilicitud de la prueba obtenida, ya que la misma se basaba en los datos obtenidos del sistema de geolocalización instalado en el vehículo puesto a disposición de la trabajadora que, si bien había sido informada de la existencia de este sistema, no lo había sido sobre la continuidad del control y de la geolocalización una vez finalizada la jornada laboral. Ello supone, de nuevo, la ilicitud de la prueba presentada por la empresa para respaldar la procedencia del despido, pues la misma había sido obtenida sin el conocimiento de la trabajadora del uso y objetivo perseguido con la instalación del dispositivo de geolocalización, ni del alcance de la misma fuera de la jornada laboral. En ambos casos, la Sala trae a colación la STC núm. 29/2013 de 11 de febrero (rec. 10522/2009), mencionada anteriormente, señalando que "no debe olvidarse que hemos establecido de forma invariable y constante que las facultades empresariales se encuentran limitadas por los derechos fundamentales", lo que supone que, si bien estos pueden verse modulados o graduados por el ejercicio de esta, no pueden ser vulnerados en el ámbito laboral.

Curiosa es la STSJ País Vasco de 2 de julio de 2007 (rec. 1175/2007) donde la colisión entre el poder de control del trabajador, manifestado a través de la implantación de un sistema de geolocalización, y la vulneración del derecho a la intimidad del trabajador, tiene que ver con la instalación de este en el teléfono móvil que la empresa pone a disposición del trabajador, y no con la instalación de dicho sistema en un vehículo. En este caso, el trabajador denuncia la vulneración de su derecho fundamental a la intimidad declarando que la prueba obtenida por la empresa para determinar que un determinado día no había realizado el servicio encargado había sido obtenida mediante el sistema de localización implantado en el teléfono móvil que tenía asignado, sin que se hubiera informado a los trabajadores de su instalación ni, claro está, del objetivo perseguido con dicho medio de control. Señala la Sala que, obviamente en este caso, el derecho a la intimidad es afectado "si el empresario utiliza un sistema de control del trabajo de sus empleados que se desarrolla fuera de sus dependencias a través de un sistema de localización permanente del teléfono móvil que se facilitan como instrumento de trabajo sin consentimiento ni conocimiento de aquellos, máxime si estos han de tenerlo a su disposición en todo momento por estar sujetos a disponibilidad permanente"11.

Igualmente, será preciso contar con el consentimiento del trabajador para mantener los sistemas de control una vez finalizada la jornada laboral, aun permaneciendo el equipo de la empresa a disposición y bajo el control del empleado.

Así lo ha seńalado la STSJ Asturias, núm. 3058/2017, de 27 de diciembre (rec. 2241/2017) en la que, ante la demanda planteada por CCOO en la que se solicita la ilegitimidad de la instalación de dispositivos GPS en los vehículos de una empresa que, pese a haber sido informados los representantes de los trabajadores y los propios trabajadores de la medida adoptada y de todo lo concerniente al tratamiento de datos y ejercicio de sus derechos de acceso, rectificación, cancelación y oposición, no consideran proporcional en tanto que el vehículo está a disposición del trabajador fuera de la jornada laboral, pues se lo llevan al domicilio y el sistema GPS sigue activo todo el tiempo sin haber sido recabado el consentimiento de los trabajadores para el control fuera del horario laboral ${ }^{12}$. La Sala entiende que, en este aspecto, la demanda debe ser estimada, y conmina a la empresa a recabar dicho consentimiento o a instalar un sistema que desactive la geolocalización una vez finalizada la jornada

\footnotetext{
${ }^{11}$ FERNÁNDEZ GARCÍA, A.: "Sistemas de geolocalización como medio de control del trabajador: un análisis jurisprudencial”, en Revista Doctrinal Aranzadi Social, núm. 17, 2010, p. 6.

${ }^{12}$ Entiende la Sala que, si bien uno de los pilares fundamentales para la licitud del control de los desplazamientos por medio de dispositivos GPS es que la existencia de una relación laboral faculta a la empresa para ejercer sus facultades de control, "cuando finaliza la jornada laboral o acaba el tiempo de trabajo, dichas facultades empresariales desaparecen y a partir de ese momento es imprescindible el consentimiento de los trabajadores para mantener en funcionamiento los dispositivos GPS”. STSJ Asturias, núm. 3058/2017, de 27 de diciembre (rec. 2241/2017) FD Quinto.
} 
laboral. Sin embargo, la misma Sala estima que, salvo en este aspecto, en el resto de cuestiones la empresa ha cumplido con su obligación y que, por tanto, la geolocalización durante la jornada laboral sí es legítima, permitiendo el funcionamiento de los sistemas siempre y cuando se cumpla con la limitación de su control al tiempo de trabajo" ${ }^{13}$. En este sentido, señala la Sala que "es indiferente que los trabajadores se hagan cargo de los vehículos que utilizan" una vez finalizada la jornada laboral, sin que el poder de control empresarial dirigido a controlar y garantizar la integridad de estos dispositivos sea suficiente para prescindir del necesario consentimiento de los afectados ${ }^{14}$.

Siguiendo el razonamiento anterior, la STSJ C. Valenciana, núm. 1165/2017, de 2 de mayo (rec. 3689/2016) se considera procedente el despido de un trabajador tras comprobar la empresa que no realizaba las visitas programadas a los clientes, gracias al mecanismo de geolocalización instalado en el vehículo que la empresa había puesto a disposición del trabajador para el desempeño de sus funciones laborales. Así, señala la Sala que no se puede considerar vulnerado el derecho a la intimidad del trabajador, en tanto que "todos los comerciales conocian la instalación de estos dispositivos porque los mismos emitían un sonido cuando se abre el vehiculo y se apaga al introducir la llave", como así corroboran otros trabajadores de la empresa. Considera, además, que la medida es proporcional, puesto que la instalación del dispositivo de localización es la única forma en que la empresa podía "controlar el destino de sus vehiculos y el modo de prestación del servicio por unos comerciales que pasaban buena parte de su jornada fuera del centro de trabajo", cumpliendo así con la finalidad perseguida, en este caso, la comprobación del trabajo realizado por el empleado ante las quejas de los clientes, quedando demostrado, además, que el "GPS permanecía inactivo durante los días de vacaciones y fines de semana", por lo que la Sala considera ésta medida como idónea en relación al fin perseguido ${ }^{15}$.

En todo caso, de la lectura del art. 87.2 LOPDyDD parece quedar claro que solo se admite que el empleador acceda a los contenidos derivados del uso de este tipo de medios cuando persiga una de las finalidades legalmente establecidas: en primer lugar, para controlar el cumplimiento de las obligaciones laborales o estatutarias y, en segundo lugar, para garantizar la integridad de dichos dispositivos; sin que la jurisprudencia haya entendido que basta perseguir esta última finalidad para permitir mantener la geolocalización en un vehículo de empresa fuera de la jornada laboral sin el consentimiento del trabajador.

Por todo ello, y con base en lo expuesto hasta el momento, parece quedar claro que la infracción por parte del empresario de su deber de elaborar criterios de utilización de los medios de la empresa fuera del tiempo de trabajo (art. 87.3 LOPDyDD) así como el incumplimiento de su deber de informar a los trabajadores afectados sobre dichos criterios determinará la vulneración del derecho a la intimidad del trabajador y, por tanto, cualquier prueba obtenida mediante dichos medios será ilícita, sin necesidad de entrar a valorar la proporcionalidad de la medida adoptada.

Por último, se debe hacer mención a la STSJ Cataluña de 23 de mayo de 2013 (rec. 6212/2012) en la que, si bien es cierto que no se trata de un caso de geolocalización, hay cuestiones que podrán afectar en el futuro a esta materia. En este caso, la empresa había instalado en los teléfonos móviles facilitados a los trabajadores de mantenimiento un acelerómetro ${ }^{16}$ que permitía conocer dónde estaban los trabajadores, cuántos pasos habían dado es día, etc. La propia Sala señala que este tipo de herramienta se encuentra instalada, de manera automática en los teléfonos actuales, complementándose con el propio sistema de geolocalización del teléfono móvil. Si bien es cierto que la empresa

\footnotetext{
${ }^{13}$ STSJ Asturias, núm. 3058/2017, de 27 de diciembre (rec. 2241/2017) FD Quinto.

${ }^{14}$ En concreto señala que "la protección por la empresa de sus bienes y el control del uso que de ellos se haga una vez terminada la jornada de trabajo no constituye una excepción a la vigencia de la indicada regla general del consentimiento". STSJ Asturias, núm. 3058/2017, de 27 de diciembre (rec. 2241/2017) FD Quinto.

${ }^{15}$ STSJ C. Valenciana, núm. 1165/2017, de 2 de mayo (rec. 3689/2016), FD Segundo.

${ }^{16}$ La propia sentencia lo define como un "elemento electromecánico que permite convertir fenómenos físicos en señales".
} 
comunicó a sus trabajadores y a los representantes de estos de la entrega del dispositivo móvil, no lo hizo sobre ésta herramienta, que había sido puesta en funcionamiento por la empresa "con el objetivo de detectar la ausencia de movimiento durante un determinado periodo de tiempo, hecho que podría suponer que el trabajador habia sufrido un accidente". De esta forma, si el dispositivo detectaba una ausencia de movimiento de más de dos minutos, lanzaba una señal acústica y un mensaje en la pantalla y, en caso de no obtener respuesta en un minuto, se avisaba directamente a emergencias, con el objeto de evitar daños mayores en la salud del trabajador. El problema real deviene de la obligatoriedad de que los trabajadores lleven el dispositivo móvil en todo momento con ellos, incluso fuera de la jornada laboral, puesto que los trabajadores eran los encargados de cargar el teléfono en sus casas. Sin embargo, la Sala acaba señalando que, si bien es cierto que el trabajador debe llevar encima el dispositivo durante la jornada laboral, no se puede deducir que el mismo supone una injerencia en su vida privada, puesto que no se sabe cuál es exactamente la actividad que este desarrolla mientras lo lleva. Tan solo detecta el movimiento normal y, en caso de no detectarlo, manda una alarma por posible accidente laboral. Dicho dispositivo, además, y pese a estar conectado con el sistema de geolocalización del teléfono, no manda ningún dato acerca de la ubicación del trabajador, limitándose la utilidad de la geolocalización a facilitar la llegada de los servicios de emergencia al lugar donde se encuentra el trabajador en caso de detectar ausencia de movimiento. Sin embargo, y pese a que la geolocalización del dispositivo no suponga una injerencia en la vida privada del trabajador, señala la Sala que sí lo hace el trasladar la responsabilidad sobre el dispositivo al trabajador fuera de la jornada laboral, incidiendo "no solo en su vida privada, sino también en lo que es esa esfera privada personal familiar que la empresa demandada no puede tener interferencia alguna, ni siquiera por motivos tecnológicos como es el caso que analizamos, pues está fuera de la jornada laboral, que es el ámbito donde la empresa y trabajador tienen que cumplir sus respectivos derechos y obligaciones"17. De esta sentencia puede deducirse que, si bien la medida no es desproporcionada ni ilegítima durante la jornada laboral, sí lo es fuera de ella, donde supone una injerencia en la vida personal del trabajador.

En definitiva, y tal como ha señalado el Tribunal Constitucional, "los derechos fundamentales no implican privar al empresario de utilizar medios que supongan una intromisión en los mismos, puesto que los derechos fundamentales no tienen carácter absoluto, y pueden ser objeto de limitaciones, siempre que estas tiendan de forma exclusiva y proporcionada a la protección de otros derechos y valores, como son la propiedad privada el empresario y la libertad de empresa"18.

\section{Los dispositivos de geolocalización en dispositivos personales del trabajador. El caso telepizza}

En el presente apartado se analizará en profundidad la SAN núm. 13/2019, de 6 de febrero (proc. 318/2018) por su interés en el análisis de los límites al uso de dispositivos de geolocalización por parte de la empresa.

El supuesto de hecho planteado es el siguiente. La empresa Telepizza decidió, de manera unilateral, poner en funcionamiento un nuevo proyecto de negocio, llamado "Proyecto Tracker", consistente en permitir al cliente la geolocalización de su pedido desde que sale del restaurante hasta la llegada a su domicilio ${ }^{19}$. Para su implantación, la empresa pasó a incluir de manera automática,

\footnotetext{
${ }^{17}$ STSJ Cataluña de 23 de mayo de 2013 (rec. 6212/2012), FD Decimotercero.

${ }^{18}$ STSJ C. Valenciana, núm. 1165/2017, de 2 de mayo (rec. 3689/2016), FD Segundo, haciendo referencia a STC núm. 186/2000 (rec. 5103/1998).

${ }^{19}$ En el HP Cuarto de la SAN núm. 13/2019, de 6 de febrero (proc. 318/2018) consta que la empresa tan solo comunicó a los representantes de los trabajadores la puesta en marcha de este proyecto, sin informar sobre la nueva exigencia a los empleados de aportar su dispositivo móvil u otras cuestiones de la aplicación práctica del proyecto.
} 
en los nuevos contratos de trabajo, una cláusula en la que se obligaba al trabajador a facilitar su teléfono móvil personal durante la jornada laboral en plenas condiciones de uso. En concreto, se exigía que la batería fuese suficiente para que el dispositivo permaneciese operativo durante la jornada laboral, que el dispositivo contase con la opción de geolocalización, que tuviese datos móviles disponibles ${ }^{20}$. Además, el trabajador debía instalar en su móvil una aplicación de la empresa, a la que debía acceder para permitir la geolocalización del pedido. Dicha aplicación podía acceder tanto a la geolocalización del dispositivo como a la cámara del mismo, pues para vincular el reparto a un determinado pedido debe acceder a un código QR que se envía al trabajador a su email personal una vez asignado el pedido a realizar. Dicho de otro modo; el trabajador debe facilitar su dispositivo móvil con acceso a su geolocalización y cámara de fotos, además de su email personal.

La nueva cláusula establece, además, una nueva causa de despido del trabajador, como es que el teléfono aportado no reúna las condiciones exigidas o la negativa del trabajador a facilitar su dispositivo para este fin empresarial. Además, añade que, en caso de ruptura o pérdida del dispositivo móvil del trabajador, "este tendrá un plazo de diez días para repararlo y ponerlo de nuevo en funcionamiento al undécimo día", momento a partir del cual la carencia del teléfono o la no aportación del trabajador de su propio teléfono supondrá la suspensión del contrato de trabajo del citado empleado "por un periodo máximo de dos meses". Una vez finalizado dicho periodo, el contrato se dará por extinguido.

Debe señalarse, por último, que la firma de esta cláusula era condición indispensable para las nuevas contrataciones, aunque voluntaria para los trabajadores que ya formaban parte de la plantilla.

Ante lo expuesto, CCOO y UGT plantean demanda de conflicto colectivo por entender que la nueva cláusula contractual es abusiva, en tanto que obliga al trabajador a aportar su propio dispositivo móvil a la actividad empresarial, y seńalan que, en todo caso, será la empresa quien deba facilitar esta herramienta. Además, también consideran abusiva la cláusula que establece como causa de despido la falta de aportación del dipositivo por parte del empleado. Por último, señalan que, el acceso por parte de la aplicación de la empresa a la geolocalización del dispositivo, así como a su cámara y galería fotográfica supone una intromisión en la privacidad del trabajador que vulnera el derecho a la intimidad el art. $18 \mathrm{CE}^{21}$.

Por su parte, la empresa aduce que esta medida se debe a la necesidad de ser competitivo en un sector en el que el resto de empresas ofrecen este servicio. Además, señala que los datos del trabajador no son conocidos por la empresa, pues su único objetivo es que el cliente conozca el estado de su pedido, y por tanto la empresa no tiene acceso a los datos, a los que solo accede el cliente. Por último, argumenta que los datos almacenados se eliminan a las 24 horas, sin que la empresa tenga acceso a ellos durante el periodo de almacenamiento ${ }^{22}$.

Tras el análisis detallado del procedimiento seguido, la Sala acaba fallando a favor de las demandas interpuestas por CCOO y UGT, haciendo referencia, en primer lugar, a que la medida implantada, "si bien obedece a fines constitucionalmente legitimos en el desarrollo del derecho a la libre empresa como son el control del empleado en el desempeño de su puesto de trabajo y la oferta de un mejor servicio al cliente - de forma que éste pueda conocer en todo momento la ubicación de su pedido, dotando a la empresa de capacidad para proporcionar servicios que se afirma ya ofrecen otras empresas del sector-no supera a juicio de la Sala el necesario juicio de proporcionalidad ${ }^{23}$. Señala así la Sala que el mismo ob-

\footnotetext{
${ }^{20}$ La cláusula completa puede consultarse en SAN núm. 13/2019, de 6 de febrero (proc. 318/2018), HP Cuarto.

${ }^{21}$ SAN núm. 13/2019, de 6 de febrero (proc. 318/2018), A.H. Sexto.

${ }^{22}$ SAN núm. 13/2019, de 6 de febrero (proc. 318/2018) A.H. Decimoquinto.

${ }^{23}$ Tal como señala MERCADER UGINA, el principio de proporcionalidad tiene especial relevancia a la hora de determinar, por parte de la jurisprudencia, la adecuación de la medida de geolocalización implantada, "de modo que deberá quedar acreditada la existencia de una necesidad especifica de la empresa (control del transporte de personas o bienes, objetivos de seguridad, planificación en tiempo real, seguimiento o facturación) para que puedan establecerse este tipo de sistemas". En MERCADER UGUINA, J.R.: El futuro del trabjao en la era de la digitalización y la robótica, Tirant Lo Blanch, Valencia, 2017, p. 152.
} 
jetivo se podría conseguir mediante otros medios que resultan menos intrusivos en la intimidad del trabajador, como puede ser la instalación de sistemas de geolocalización en los vehículos para reparto de la empresa, o facilitando al trabajador una pulsera con este dispositivo para que la lleve durante la jornada laboral; "que no implican para el empleado la necesidad de aportar medios propios y lo que es más importante, ni datos de carácter personal como son el número de teléfono o la dirección de correo electrónico en la que han de recibir el código de descarga de la aplicación informática que activa el sistema"24.

En segundo lugar, alude a los arts. 12 y 13 de la anterior LOPD y arts. 11 y 90 de la actual LOPDyDD en materia de obligación de información y acceso a los datos y a su art. 90 en relación al sistema de geolocalización de empleados. En concreto, los arts. 11 y 90 LOPDyDD establecen el derecho de las personas a ser informados por el responsable de tratamiento de datos "sobre los medios a su disposición para ejercer los derechos que le corresponden", así como el derecho del afectado de acceder a los datos almacenados, que deberá ser "un sistema de acceso remoto, directo y seguro a los datos personales que garantice, de modo permanente, el acceso en su totalidad". A este respecto, se manifiesta la Sala señalando que "para la implantación del sistema de geolocalización por parte del empleador se ha prescindido de proporcional a los trabajadores la información a la que se refieren los arts. 12 y 13 LOPD”. También se señala que se ha vulnerado el contenido del art. 90.2 LOPDyDD, pues el mismo establece que "con carácter previo, los empleadores habrán de informar de forma expresa, clara e inequivoca a los trabajadores y a sus representantes acerca de la existencia y características de estos dispositivos. Igualmente deberán informarles acerca del posible ejercicio de sus derechos" de acceso, rectificación, cancelación y oposición. Como queda mostrado, la cláusula contractual que obligan a firmar a los nuevos trabajadores, no incluye esta información, que además no ha sido facilitada de ninguna otra manera a los empleados, por lo que la medida supone una vulneración de los derechos de los trabajadores respecto a sus datos personales y, por tanto, una intromisión en su intimidad ${ }^{25}$.

Por tanto, la Sala apoya su decisión, por una parte, en el juicio de proporcionalidad, concluyendo que la medida de control es desproporcionada, además de innecesaria por existir medios de control menos invasivos que el utilizado ${ }^{26}$. Por otra parte, y de manera complementaria, hace un juicio de contenido esencial, al señalar que la empresa no facilitó a los trabajadores la información que está obligado a facilitar legalmente.

\section{Conclusiones}

A la luz de la jurisprudencia analizada y de la reciente LOPDyDD, se puede concluir que, para que la geolocalización del trabajador en su jornada laboral sea legítima debe cumplir las siguientes características:

- El sistema de geolocalización deberá estar instalado, preferentemente, en un dispositivo o vehículo propiedad de la empresa, no del trabajador, pues es la empresa la encargada de facilitar las herramientas para el desempeño adecuado de las funciones laborales.

- En todo caso, la finalidad debe limitarse al control de la actividad laboral, por lo que no estará permitida para otras finalidades distintas o fuera de la jornada laboral, aunque el dispositivo sea propiedad de la empresa.

- El trabajador debe haber sido informado de manera previa, expresa, clara e inequívoca, sobre el medio de geolocalización instalado y su finalidad, así como sobre la información

\footnotetext{
${ }^{24}$ SAN núm. 13/2019, de 6 de febrero (proc. 318/2018), FD Sexto.

${ }^{25}$ SAN núm. 13/2019, de 6 de febrero (proc. 318/2018) FD Sexto.

${ }^{26}$ SAN núm. 13/2019, de 6 de febrero (proc. 318/2018) FD Séptimo.
} 
y derechos de acceso, rectificación, cancelación y oposición recogidos en los arts. 12 y 13 LOPDyDD; EN LOS TÉRMINOS DEL ART. 5.1 LOPD ${ }^{27}$.

Por todo lo anterior, y teniendo en cuenta otras sentencias analizadas a lo largo del presente artículo, la falta de información sobre la implantación del control de geolocalización, así como el tratamiento de datos obtenidos a través de la misma y sobre los derechos de acceso, rectificación, cancelación y oposición supondrá la nulidad del despido.

En todo caso, y como se ha señalado a lo largo del texto, en el supuesto de que el empleador incumpla su deber de elaborar criterios de uso de los equipos de trabajo o no informe a los trabajadores sobre dichos criterios, cualquier prueba obtenida mediante la localización, incumpliendo estas cuestiones, deberá ser valorada como ilícita, en tanto que ha sido obtenida vulnerando el derecho fundamental a la libertad del trabajador.

Por otra parte, en relación al sistema de geolocalización que sigue en funcionamiento una vez ha finalizado la jornada laboral, debe señalarse que, en primer lugar, para poder continuar geolocalizando el equipo de trabajo fuera del tiempo de trabajo cuando éste quede a disposición del empleado, éste deberá haber prestado su consentimiento, en tanto que es posible que no solo se obtengan datos de la localización del vehículo o dispositivo móvil sino del propio trabajador que lo porta. En todo caso, y en aras de proteger el derecho a la desconexión digital recogido en el art. 88 LOPDyDD, el tiempo de descanso deberá ser respetado por el empresario, lo que impedirá su localización y control fuera de la jornada de trabajo, por lo que los datos obtenidos durante este tipo no podrán ser utilizados con fines distintos al de garantizar la seguridad de los propios equipos de trabajo.

Si algo parece claro tras el análisis de la SAN núm. 13/2019 de 6 de febrero (proc. 318/2018) es que la empresa no puede obligar al trabajador a aportar su propio dispositivo móvil con el objeto de geolocalizarle a través del mismo. Esto, con los actuales cambios que se viven en el ámbito laboral, en concreto en el nuevo empleo a través de plataformas digitales, parece que deberá ser tenido en cuenta. El empleo en plataformas digitales se basa en la aportación, por parte del trabajador, del dispositivo móvil mediante el que es localizado y a través del cual le llegan los pedidos tras descargarse y acceder a la plataforma digital propiedad de la empresa. Parece ser que, tras esta sentencia y siempre que estos trabajadores sean considerados asalariados, no será posible que estas plataformas utilicen el dispositivo móvil del trabajador como herramienta de trabajo y geolocalización, en tanto que la Sala considera que se vulnera el derecho a la intimidad del trabajador.

En todo caso, si bien el contenido y el razonamiento de la SAN núm. 13/2019, de 6 de febrero (proc. 318/2018) es adecuado, se debe considerar que el procedimiento seguido en su valoración es erróneo en cuanto al orden, debiendo haber analizado los incumplimientos empresariales de manera inversa. Ello se debe a que, con base en el art. 53.1 $\mathrm{CE}^{28}$, el contenido esencial del derecho fundamental a la intimidad no podrá verse afectado en ningún caso, por lo que deberá ser la primera cuestión a analizar, antes del juicio de proporcionalidad, ya que no será necesario analizar el segundo si no se ha superado previamente el primero.

Igualmente, el sometimiento del trabajador a un sistema de geolocalización por parte de la empresa, puede servir como prueba de laboralidad por revelar la nota de dependencia, tal como señaló la STSJ Castilla-La Mancha núm. 959/2017, de 29 de junio (rec. 430/2017).

Todo lo anterior lleva a la pregunta de cómo afectará la nueva regulación y la última jurisprudencia al futuro laboral, teniendo en cuenta la aparición de empresas que basan su negocio en el uso de los trabajadores de su propio dispositivo móvil, incluyendo el acceso a datos personales y

\footnotetext{
${ }^{27}$ Así lo exige la Agencia Española de Protección de Datos en su Informe 193/2008.

${ }^{28}$ En concreto, el art. 53.1 CE establece que se deberá respetar siempre el contenido esencial de los derechos fundamentales.
} 
a la geolocalización. Parece razonable estimar que, cuando se reconozca la laboralidad de la relación entre una plataforma y el colaborador, la primera ya no podrá exigir al segundo que facilite su dispositivo móvil personal en condiciones adecuadas de uso y con acceso a ciertas utilidades del mismo, como puede ser la geolocalización, a lo largo de su jornada laboral. En todo caso, deberá ser la empresa quien facilite la herramienta de trabajo y el medio de control, informando siempre de este último en consecuencia con la LOPDyDD. En todo caso, la facultad de control empresarial nunca se extenderá más allá de la prestación del servicio, cosa que parece hacerse ahora en los servicios prestados a través de plataformas digitales, en tanto que el trabajador debe estar geolocalizado y dentro de la aplicación de la empresa, aun cuando no se encuentra prestando servicios de manera efectiva, en lo que la propia empresa llama "tiempos de espera o disponibilidad"; cuestión esta que deberá ser analizada y abordada por la doctrina y que en un futuro no muy lejano, llegará a los tribunales espańoles para ser resuelta garantizando, tanto el poder de control del empresario como los derechos a la intimidad y al acceso, rectificación y cancelación de los datos personales del trabajador en la relación laboral.

\section{Bibliografía}

Agencia Española de Protección de Datos en su Informe 193/2008

Fernández Domínguez, J.J. y Rodríguez Escanciano, S.: Utilización y control de datos laborales automatizados, Agencia de Protección de Datos, Madrid, 1997.

Fernández García, A.: "Sistemas de geolocalización como medio de control del trabajador: un análisis jurisprudencial”, en Revista Doctrinal Aranzadi Social, núm. 17, 2010.

González González, C.: "Control empresarial de la actividad laboral mediante la videovigilancia y colisión con los derechos fundamentales del trabajador. Novedades de la Ley Orgánica 3/2018, de 5 de diciembre, de Protección de Datos Personales y garantía de los derechos digitales", en Aranzadi Digital, núm. 1/2018

GonzÁlez GonzÁlez, C.: "Control empresarial de la actividad laboral, videovigilancia y deber informativo. A propósito de la STC de 3 de marzo de 2016”, en Revista Aranzadi Doctrinal, núm. 5, 2016.

GoÑ SEIN, J.L.: "Nuevas tecnologías digitales, poderes empresariales y derechos de los trabajadores. Análisis desde la perspectiva del Reglamento Europeo de Protección de Datos de 2016", en Revista de Derecho Social, núm. 78, 2017.

Llorens Espada, J.: "La negociación colectiva como fuente reguladora en el tratamiento de datos y los nuevos derechos digitales", en El futuro del trabajo. 100 años de la OIT. XXIX Congreso Anual de la Asociación Española de Derecho del Trabajo y de la Seguridad Social, Ministerio de Trabajo, Migraciones y Seguridad Social, 2019, pp. 1435-1455.

Martínez Fons, D.: El poder de control del empresario en la relación laboral, CES, Madrid, 2002.

Mercader Uguina, J.r.: El futuro del trabjao en la era de la digitalización y la robótica, Tirant Lo Blanch, Valencia, 2017.

Sempere Navarro, A.v. y San Martin Mazzucconi, C.: Nuevas tecnologias y relaciones laborales, Aranzadi, Cizur Menor, 2002.

Tascón López, R.: "El lento (pero firme) proceso de decantación de los límites del poder de control empresarial en la era tecnológica", en Revista Doctrinal Aranzadi Social, núm. 17, 2007.

Jurisprudencia consultada

STC núm. 29/2013, de 11 de febrero (rec. 10522/2009),

STC núm. 254/1993, de 20 de julio (rec.1827/1990). 
STC núm. 186/2000 (rec. 5103/1998)

SAN núm. 13/2019, de 6 de febrero (proc. 318/2018)

STSJ Asturias, núm. 2191/2017, de 3 de octubre (rec. 1908/2017)

STSJ Asturias, núm. 3058/2017, de 27 de diciembre (rec. 2241/2017)

STSJ Cataluńa de 23 de mayo de 2013 (rec. 6212/2012)

STSJ C. Valenciana, núm. 1165/2017, de 2 de mayo (rec. 3689/2016)

STSJ Madrid núm. 260/2014, de 21 de marzo de 2014 (rec. 1952/2013)

STSJ Madrid, núm. 739/2014 de 29 de septiembre (rec. 1993/2013)

STSJ País Vasco de 2 de julio de 2007 (rec. 1175/2007) 